\title{
Organizational Management Culture and Employers' Health Insurance Offering strategies in the US: An Ubuntu Based Random Utility Modeling Approach
}

\author{
Ibrahim Niankara \\ College of Business, Al Ain University of Science and Technology, P.O. Box: 112612, Abu Dhabi, UAE; Tel: \\ +97124444696 Ext: 539 ; Fax: +97124444304; E-mail: ibrahim.niankara@aau.ac.ae
}

\begin{abstract}
This article takes an approach to explaining the behavioral manifestations of the decision making in US companies' offer of health insurance that is grounded not only on their cost minimizing behavior, but also in a humanness dimension based on the African concept of Ubuntu. In this way, we define an Ubuntu based Random Utility modeling framework, describing the choice process as a tripartite decision making, and implemented using a nationally representative random sample of 1,061 American companies from the Dunn and Bradstreet Business data, supplied by Survey Sampling International to the Associated Press-NORC Center for Public Affairs Research.

The results from the three sequentially implemented specifications showed that the relationship between management culture and health plan offering strategy is dependent on other relevant co-variates, which when left out, leads to the problem of omitted variables bias. However, when all variables are included but assumed to enter the relationship exogenously, this results in management culture not having any statistically significant effect on companies' decisions about scope of health plan offering. When the exogeneity assumption is relaxed through a recursively Bivariate Probit model, the system of two equations produces a highly significant management culture effect. In fact, in this later case we see that companies with groups and formal committee management culture are 1.58 times less likely to choose a multiple plan strategy over a single plan strategy, hence failing to show the more wholesome plan offering that would theoretically prevail under Ubuntu style management.
\end{abstract}

Keywords: Affordable Care Act, Discrete Choice Modeling, Employer Health Insurance, Ubuntu JEL: C10, C50, I13, J2, M52 


\section{Introduction}

Described as the equivalent of "private social security," employer-sponsored insurance is a cornerstone of the U.S. health care system, as vital in some ways to the health care and well-being of Americans as the drugs, devices, and medical services that the insurance covers(Blumenthal, 2006). Understanding the employer-sponsored health insurance market is therefore central to understanding the U.S. health care system as a whole. However, much of the literature on Employer-provided Health insurance has focused on the factors affecting workers' insurance coverage decisions (Shane and Ayyagari, 2015; Look and Arora, 2015; Look et al., 2016). Relatively fewer studies (Vistness and Monheit, 1999; O'Brien, 2003; Collins et al., 2005) have looked at employers' decisions to offer the Health coverage in the first place. Because a market is defined by both the Demand and Supply side (Blumenthal, 2006), understanding employers' health plan offering decisions brings about more light to the overall functioning of the Employer-Sponsored Health Insurance Market (Goldstein and Pauly, 1976).

In general, the process of Health insurance decision making by employers is the product of concurrent actions and interactions among multiple individuals (Johns, 2006). This is to say that companies do not make health insurance decisions, individuals within the companies do. This observation is a statement of both structural and operational fact: companies (as physical realities, not accounting or legal entities) are all created, supported, maintained and operated by people. Thus, the issue of socially constrained, but nevertheless individual decision making, lies at the heart of companies' health plan decision making (Carley and Behrens, 1999).

In the United States, Company's offering of health insurance is heavily regulated (Holtz-Eakin and Smith, 2010). Some legislation and rules such as the tax exemptions on health insurance expenses are intended to incentivize insurance offering by firms through lowering their costs, while other rules such as many state mandates (Flynn et al., 1997) and some provisions of the recently legislated Affordable Care Act (ACA) (Shane and Ayyagari, 2014) are designed to ensure equity in coverage. Generally the later rules require coverage of specific treatments or health conditions, and tend to raise costs, as such desincentivize insurance offering by firms(Baicker and Levy, 2008).

Before the changes introduced under the ACA, there had been an ongoing decline in employerprovided Health Plan coverage (Blavin et al., 2015b). For example, between 2000 and 2012, coverage rates for non-elderly workers (ages 18 to 64) fell $11 \%$, from $76.9 \%$ to $69.4 \%$. Among workers in firms with fewer than 50 employees, coverage rates fell $17 \%$, from $61.1 \%$ to $52.4 \%$ (Blavin et al., 2015a). While critics believes ACA accelerates this trend as the greater availability of coverage outside of work would make it easier for employers to stop offering coverage, others believe ACA's requirements have a negligible impact on total employer-sponsored coverage and its costs(Blumberg et al., 2012).

In light of these controversies, this study aims to investigate the contribution of organizational management culture in shaping health plan offering strategies in the US under the ACA. In fact, 
the management culture adopted by a company often reflects the overall culture in which it is surrounded by. In some ways however western cultures are different from the African culture - in an African framework, social and cultural linkages are considered to be a key determining factor for the success of any institution operating on the continent Mangaliso, 2001; Smith and Lindsay, 2014). The implication is that people must come first, before products, profits and productivity. Once people have been given priority and are treated well in their daily endeavors, productivity, products and profits should automatically be realized. As Jackson (2004) puts it :

"Conflicts between African and Western values are evident in numerous aspects of managerial work. The African managerial style places greater emphasis on moral rather than on material incentives. Moral incentives are considered to be more meaningful and long-lasting. Indeed, wages are the property of the family not the individual; consequently, monetary incentives have little effect in performance, unless they are paid to the collectively.... Western management approaches presume the desirability of taking risks, and value work motivation. In most African countries, the quality of life, and the value attached to personal time exceed any desire to accumulate wealth. Positive interpersonal relationships are valued above money".

This view shows an African organizational management system, different from the classical western management systems, that takes into account the socio-cultural attributes of the company in conformity with the African principle of Ubuntu. However, the caring and sharing concept that forms the core of the African Ubuntu philosophy is now well recognized and accepted globally. Modern corporations are more and more realizing that they are a part of the local communities within which their operations are conductedOwolabi and Olu-Owolabi (2009), and many global leaders are advocating the values of Ubuntu. For example, former president of the United States, Bill Clinton, embracing the Ubuntu philosophy invited the Labour Conference in the United Kingdom to do the same(BBC News,2006, in (Khomba and Kangaude-Ulaya, 2013)):

"All you need is Ubuntu. Society is important because of Ubuntu. If we were the most beautiful, the most intelligent, the most wealthy, the most powerful person - and then found all of a sudden that we were alone on the planet, it wouldn't amount to a hill of beans."

The US Department of State also acknowledged and accepted the Ubuntu philosophy through its ambassador Elizabeth Frawley Bagley, the Secretary of State's Special Representative for Global Partnerships when she expounded positively on the concept of the Ubuntu philosophy as she was being sworn into office (US Government, 2009, in (Khomba and Kangaude-Ulaya, 2013)):

"The concept of Ubuntu dates back centuries and appears in various forms in traditions throughout the world; and yet globalization has heightened our awareness of this interconnectedness. In the same way that Secretary [Hillary] Clinton has often said that It takes a village to raise a child, we are now realizing that we must apply a similar approach worldwide. This is the Ubuntu Diplomacy where all sectors belong as partners, where we all participate as stakeholders, and where we all succeed together, not incrementally but exponentially".

Thus, the inclusion of the Ubuntu philosophy into western organizational systems is enabling 
US companies to become more responsive to the call for corporate social responsibility and good corporate governance. The founding principles of business ethics and corporate governance in line with the Ubuntu philosophy regard all members of an organization as part of the community, and bring about greater solidarity, love, caring and sharing within the organization (Sigger et al., $2010)$.

In relation to US employers' health insurance provision, Ubuntu style management implies that companies need to see whether their choices of plan offering are enabling and empowering employees and helping them contribute to the successful functioning of the company, and the community. This can be achieved when companies' scope of plan offering expresses the heterogeneity of employees health insurance preferences (Hirth et al., 2006; Maxwell, 2011). Therefore, in the following we investigate companies health plan offering strategies in the US to see if enough evidence exist to suggest that under some regularity conditions, namely groups and formal committee management cultures, western style management can lead to outcomes theoretically expected under the Ubuntu style management.

The question this research addresses is: "Given the competitive business environment in the US, compared to companies with an individual management culture, are companies with groups and formal committee management cultures more prone to choosing a multiple plan offering strategy over a single plan strategy?"

The maintained hypothesis is that groups and formal committee management cultures are more in line with Ubuntu style management than the individual management culture. Put differently, the probability of choosing a multiple plan offering strategy over a single plan strategy is higher for companies with groups and formal committee management cultures, than those with an individual management culture.

In our quest to test the above formulated hypothesis, the remaining of this research article is organized as follows: Section 2 discusses the Ubuntu philosophy, and how Ubuntu style management can affect employers scope of health plan offering. Section 3 presents an Ubuntu based Random Utility Model of Employers Insurance Offering Strategies. Section 4 describes the data and the variables used in the econometric modeling. Section 5 presents the results of the estimated model, while section 6 concludes the analysis

\section{Ubunto Philosophy, Ubuntu Style Management and Scope of Health Plan Offering}

Emerging African management philosophies see any organization as a community and can be summed up in one word - Ubuntu (Mbigi and Maree, 2005). Derived from the Nguni (isiZulu) aphorism "Umuntu Ngumuntu Ngabantu", and translated as "a person is a person because of or through others" (Tutu and Abrams, 2004; Fraser-Moleketi, 2009), Ubuntu is described as the human capacity to express compassion, reciprocity, dignity, humanity and mutuality in the interests of building and maintaining institutions with justice and mutual caring (Lutz, 2009, Muchie et al. 
2009; Tutu, 2012). According to Eze (2010), the core of this philosophy strikes an affirmation of one's humanity through recognition of an 'other' in his or her uniqueness and difference.

"It is a demand for a creative inter-subjective formation in which the 'other' becomes a mirror (but only a mirror) for my subjectivity. This idealism suggests to us that humanity is not embedded in my person solely as an individual; my humanity is co-substantively bestowed upon the other and me. Humanity is a quality we owe to each other. We create each other and need to sustain this otherness creation. And if we belong to each other, we participate in our creations: we are because you are, and since you are, definitely I am. The 'I am' is not a rigid subject, but a dynamic self-constitution dependent on this otherness creation of relation and distance".

As a people-centered philosophy, Ubuntu stipulates that a person's worth depends on social, cultural and spiritual criteria. It requires a life that depends on a normative engagement with the whole, a substantive appreciation of the common good and a constitutive engagement with one another in a rational and ethical institution (Wanasika et al., 2011). Equally important in Ubuntu relationships is the aspect of working with others as a team (Mangaliso, 2001; English, 2002). African Ubuntu management system recognizes the significance of group solidarity that is prevalent in African cultures, acknowledging that an African leadership style involves group and community supportiveness, sharing and cooperation. A spirit of solidarity simultaneously supports cooperation and competitiveness amongst the team by allowing individuals to contribute their best efforts for the betterment of the entire group (English, 2002, Smith and Lindsay, 2014).

Within a company, the existence of Ubuntu as a shared value system implies that employees are encouraged to strive towards the outlined values, which consequently enhance their functioning as an institution (Wanasika et al. 2011). The company is brought one step closer to being effective because of the increased level of employees' commitment, loyalty and satisfaction, which ultimately has a positive impact on overall performance Khomba and Kangaude-Ulaya (2013) . Ubuntu can help companies gain competitive advantages on the basis of several business premises, including effective human relationships with others, language and communication, decision-making, time management, productivity, leadership, and cultural beliefs (Mangaliso, 2001; Smith and Lindsay, 2014).

Other things being equal, "Ceteris Paribus", Ubuntu style Management, which combines philosophical ethics with Organizational theory(Hosmer, 1995) to form a more humane management style should theoretically lead to a multiple plan offering strategy (over the single plan strategy) to cover the heterogeneous health insurance preferences of employees, and thereby guarantee more worker's satisfactions in regards to their health insurance needs, and consumption.

In fact, under the Ubuntu view, companies loose their impersonal nature that led to the traditional profit maximization goal at all costs, to embrace a more wholesome and inclusive view which considers profit maximization as an important goal, but adds some humanness dimension to the overall pursued objective. In doing so, the classic distinction of Utility maximization by the consumption side, and Profit maximization by the Production side, is reconciled into a 
single welfare (or overall utility of all company's stakeholders) maximization. The current study, grounded on this Ubuntu view of organizational management defines firms' decision on the scope of health plan offering for its employees in the US as a tripartite process described as Follows :

1. Choose the Organizational Management Style: By defining whether decisions will be made by i) a group of Employee, or ii) A formal Committee, or iii) an individual. The outcome of this process is captured here by the Binary Variable

OrgManCu $=1$ if the Business chooses to have a "Group of employees or Committee Management culture", and $=0$ if the Business chooses an "Individual only Management culture."

2. Choose whether or not to offer Health insurance: Once the Management Style is defined then the chosen decision making unit should define whether or not the company will provide health insurance coverage for its employees. The outcome of this process depends not only on the fixed costs of plan offering by the company, but also on state and federal government mandates, such as those from the ACA. This outcome is captured by the Binary Variable Offer $=1$ if the company "decides to offer health Insurance to its employee", and $=0$ if the company "decides not to offer health insurance to its employee."

3. Choose the scope of the Offering, or Plan offering strategy: Once the decision to offer health insurance has been made, then the decision making unit must define the scope of plan offering. That is whether the company will offer only one plan for all its employees, or offer several plans. The outcome of this process depends on the company's marginal costs of plan offering (not in terms of scale of the offering, but in terms of scope of the offering). This outcome is captured by the Binary Variable

OrgHPofS $=1$ if the Business chooses a "Multiple-Plan Offering Strategy" , and =0 if the Business chooses a "Single-Plan Offering Strategy."

The premise underlying the implemented modeling strategy lends itself to the discrete choice framework derived here under the assumption of welfare maximization behavior by the organizational decision making unit. This unit is assumed to be rational and to make health plan offering decisions on the basis of factors related to the internal and external environments of the company. Although many factors affect this choice process, the contention in this paper is that the company's management culture itself is a major determinant of whether a company chooses a single plan offering strategy or a multiple plan offering strategy. Therefore, for the above described three processes leading to the choice of the final scope of health insurance plan offering by a company, we rely on what can be defined as an Ubuntu Based random utility modeling framework to describe the sequential choices made at each stage.

\section{Ubuntu Based Random Utility Model of Employers Insurance Offering strategies}

In the Ubuntu based random utility formulation it is assumed that at each of the three stages, the organizational decision making unit chooses between two alternatives indexed respectively with 
zero (0) and one (1), according to which one provides the greatest welfare/satisfaction. In the first stage the choice is between 1- "Group of employees or Committee Management culture", and 0"Individual only Management culture". In the Second Stage of the decision process, the choice is between 1- decide "to offer health Insurance to its employees", and 0 - decide "not to offer health insurance to its employees". Finally in the third stage the choice is between 1- "Multiple-Plan Offering Strategy" , and 0- "Single-Plan Offering Strategy". At each stage the organizational decision making unit chooses the alternative with the highest satisfaction/Utility/welfare. Therefore in the first stage, the discrete outcome variable of the process (OrgManCu) takes the value 1 if alternative 1 has the greater utility of the two, otherwise OrgManCu $=0$. Similarly in the second stage, the discrete outcome variable (Offer) takes the value 1 if alternative 1 has the greater utility of the two, otherwise Offer $=0$. Finally, and same as the first two stages, the discrete outcome variable (OrgHPofS) takes the value 1 if alternative 1 has the greater utility of the two, otherwise OrgHPofS $=0$. Additive random utility modeling (ARUM) specification gives the utilities of alternatives 0 and 1 at each stage $i$ for $i=1,2,3$ to be:

$$
\begin{aligned}
& U_{i 0}=V_{i 0}+\epsilon_{i 0}, \\
& U_{i 1}=V_{i 1}+\epsilon_{i 1},
\end{aligned}
$$

where $V_{i 0}$ and $V_{i 1}$ are deterministic components of utility with $\epsilon_{i 0}$ and $\epsilon_{i 1}$ being the random components of utility. We observe $y_{i}=1$, if $U_{i 1}>U_{i 0}$, that is if alternative 1 has the highest utility of the two. Because of the presence of the random components of utility this is a random event with

$$
\begin{aligned}
\operatorname{Pr}\left[y_{i}=1\right] & =\operatorname{Pr}\left[U_{i 1}>U_{i 0}\right] \\
& =\operatorname{Pr}\left[V_{i 1}+\epsilon_{i 1}>V_{i 0}+\epsilon_{i 0}\right] \\
& =\operatorname{Pr}\left[\epsilon_{i 0}-\epsilon_{i 1}<V_{i 1}-V_{i 0}\right] \\
& =F\left(V_{i 1}-V_{i 0}\right)
\end{aligned}
$$

where $F($.$) is the cumulative distribution function of the error differences \left(\epsilon_{i 0}-\epsilon_{i 1}\right)$. giving

$$
\operatorname{Pr}\left[y_{i}=1\right]=F\left(X^{\prime} \beta_{i}\right) \text { if } V_{i 1}-V_{i 0}=X^{\prime} \beta_{i}
$$

The ARUM requires a scale normalization since, if $U_{i 1}>U_{i 0}$ then $a U_{i 1}>a U_{i 0}$. This is usually done by specifying the variance of $\left(\epsilon_{i 0}-\epsilon_{i 1}\right)$. Different parametric specifications for the distributions of the error terms $\left(\epsilon_{i 0}\right)$ and $\left(\epsilon_{i 1}\right)$ give different $F($.$) and hence different discrete choice models.$

The Logit model or logistic regression is obtained when $F\left(X^{\prime} \beta_{i}\right)=\Lambda\left(X^{\prime} \beta_{i}\right)$, that is the type 1 extreme value cumulative distribution function. The Probit model (R Core Team, 2015, glm(stats)) is obtained when $F\left(X^{\prime} \beta_{i}\right)$ is assumed to be the standard normal cumulative distribution function. 
We may also define semi-parametric to fully non-parametric distributions for $F\left(X^{\prime} \beta_{i}\right)$ and use appropriate semi-parametric (Malgorzata et al., 2016) and non-parametric (Hayfield and Racine, 2008) methods to estimate the choice probabilities in the model. If we assume each stage to be an independent process, then we can estimate the three processes separately using appropriate univariate methods, if however we make the assumption that the three are interrelated, then the overall problem becomes a tri-variate modeling situation with 3 systems of equations to be estimated jointly using appropriate multivariate methods.

\section{Data and Variable Descriptions}

The current study uses data from a 2014 Survey of Businesses in the United States " Employer Perspectives on the Health Insurance Market". The survey investigated health insurance benefits offering by private-sector employers as key components of the Affordable Care (ACA) were being implemented. This nationally representative survey of employers is the result of a computerassisted telephone interview (CATI), from August 19, 2014 to October 8, 2014 on a random sample of 1,061 businesses from the Dunn and Bradstreet business data which was supplied by Survey Sampling International. A total of $(n=445)$ businesses were interviewed via the web, while the remaining $(n=616)$ were interviewed through telephone. Respondents were offered a $\$ 50$ monetary incentive for participating, as compensation for their time. A "most knowledgeable respondent" method was used to select the respondent in the organization who could best answer the survey. $31 \%$ of respondents identified themselves as business owners, $30 \%$ as office managers, $18 \%$ as executive officers, $11 \%$ as human resources managers, $2 \%$ as benefits managers, $2 \%$ as project managers, and $6 \%$ as another position.

The employers were interviewed about the types of health benefits they offered to employees and dependents, reasons for offering health insurance, and key considerations when choosing health insurance plans with an emphasis on sources of information used to evaluate health insurance plan quality. Additional topics covered by the survey include changes in insurance carriers or decisions to offer additional plans with a new insurance carrier, and how employers planned to react to the ACA requirement that employers with 50 or more full-time employees offer coverage to at least 70 percent of full-time employees or face financial penalties. The dataset which were made available through the world bank micro-data library home, was collected by the Center for Public Affairs Research with funding provided by the Robert Wood Johnson Foundation. Of the total of 1,061 businesses interviewed, our study included 758 businesses after accounting for missing data constraints and variables selections. For more details on the data refer to (Public Affairs Research Center, 2014).

Now given that ACA mandates constraints employers with 50 or more full-time employees to offer coverage to their full-time employees, the second step of the overall tripartite decision making process is not as relevant in the overall choice problem facing the organizational decision 
making unit. Furthermore, the above described sample is restricted to only companies providing some private coverage (for which Offer $=1$ ), therefore as a selected sample, it excludes the situation where "Offer $=0$ ", that is the employer doesn't provide any form of coverage, as such we can safely do away with modeling the second step consisting of choosing whether or not to offer health insurance. This allows us to redefine our tri-variate modeling problem into a bi-variate modeling one, with the two outcome variables described as shown below:

\subsection{The Binary Organizational Management Culture}

This outcome variable captures the type of management culture adopted by the company for decision making purposes. For our analysis, the companies ascribe to one of two types of management cultures. An "Individual Management culture", or a "group of employees or committee management culture". Therefore the binary variable is defined as:

OrgManCu $=1$ if the Business has a "Group of employees or Committee Management culture" , and $=0$ if the Business has an "Individual only Management culture"

\subsection{The Binary Organizational Health Plan Offering strategy}

This outcome variable captures the strategy adopted by the company in its offering of health plan. For our analysis, the companies ascribe to one of two types of strategies. A "Single-Plan offering strategy", or a "Multiple-Plan offering Strategy". Therefore the binary variable is defined as:

OrgHPofS $=1$ if the Business has a "Multiple-Plan Offering Strategy" , and $=0$ if the Business has a "Single-Plan Offering Strategy"

\subsection{Independents variables}

Like any scientific study using evidence from observational data, our interests here centers on a postulated causal influence from the attributes and environments of the companies to their responses, or chosen health plan offering strategies. It is assumed that these health plan choices in 2014 will reflect US companies' degree of adoption of the Ubuntu philosophy as embraced and promoted by former president Bill Clinton in 2006, the US Department of State through the Secretary of State Hillary Clinton, and Ambassador Elizabeth Frawley Bagley on june of 2009. So in choosing the covariates to be included in the model, the question that needs to be addressed is: In addition to a company's management culture, what other factors affect the choice of scope of health plan the company offers?

The primary goal of this empirical analysis is not to model the determinants of companies' health plan offering strategies in the US, but to measure the impact that management culture has on influencing the offering strategies adopted by the companies. In order to achieve the study goal however, we need to account for the effects of other covariates affecting this relationship such as a company's for-profit status, Industry of operation, number of full-time employees, the position 
of the chosen employee respondent in the company, that employee's perception of ACA effect on his/her company's plan offering decisions; whether or not the company has access to a source of quality information, and finally whether the plan(s) offered by the company have High Deductibles ( that is: have an annual single deductible of at least $\$ 1,250$ and a family deductible of at least $\$ 2,500$ for in-network). Table (1) provides definitions and summary statistics for the variables.

\section{Econometric results and Interpretation}

Given the aim of the analysis, to evaluate the impact of organizational management cultures on companies' chosen health plan offering strategies, we've specified and estimated three regression models. The first one is a univariate (un-adjusted) regression model, with only the binary management culture as an explanatory variable. The second specification acknowledges the existence and importance of other covariates, hence leading to a single equation multivariate (single - Adjusted) regression model, which assumes exogenous effects from all explanatory variables in the model. The third and last specification also takes into account other explanatory variables, but relaxes the exogeneity assumption in the second specification, to define a Bivariate (double-Adjusted) regression model with a binary endogenous management culture variable, and formulated as a system of two equations. This last specification corresponds to our probabilistic Ubuntu Based Random Utility Economic model formulated in equation (3), with the second step ( $\mathrm{i}=2$ ) omitted as previously explained. In doing so, the tri-variate model simplifies to a bi-variate one. The value of these three specifications is in allowing us to test the robustness of the relationship between adopted management culture and health plan offering strategy, to potential problems of omitted variable biases and mi-specification issues.

The first two specifications are estimated with standard logistics regression methods using the "glm" function from the "stats" library within the R statistical software (R Core Team, 2015, $\operatorname{glm}($ stats)), while the third specification is estimated using semi-parametric Gaussian Copula methods with Bernoulli margins for the two equations in the system (Malgorzata et al., 2016). All results are shown in the table(2).

\subsection{Results from the Un-Adjusted and Single-Adjusted Logistic regressions}

The un-adjusted logistic results in the first column of table (2) suggest that, not accounting for other variables, companies' with a group of employees or a committee management culture, when deciding on the scope of plan offering tend to provide more than one plan, compared to companies where a single person makes the decision on plan offering. In fact, the positive and highly significant coefficient value of 0.637 for the binary management culture confirms this conclusion. Using the odds ratio representation to get the marginal effects, then exponentiation of this coefficient gives an odd of 1.89 times in favor of companies with groups or formal committees cultures, in the choice 
of a multiple plan offering strategy. This odds ratio is statistically significant as shown by the $95 \%$ confidence interval $(1.336,2.694)$.

Now moving into accounting for the effects of the other variables that might affect companies' health plan offering decisions, the results of the single-Adjusted Model shown in the second column of table (2) clearly suggest the presence of omitted variables Bias problems in the first formulated model in column one. In fact, this specification which implicitly assumes that all the included explanatory variables are exogenous, shows that organizational management culture, although significant in the un-adjusted formulation is no longer relevant to the contemporaneous health plan offering decisions by companies. Also interesting to note is that a company's for profit status, and the respondent's perception of ACA effects on company's plan offering strategies are all statistically insignificant in predicting the company's contemporaneous scope of plan offering.

On the opposite however, the single-adjusted model results in the second column do suggest that factors such as the number of full time employees, whether or not the company is offering a high deductible plan, whether the company has access to a source of quality information to help with its plan offering decisions, the current position held by the respondent within the company, and finally the industry in which the company is operating, are all factors with statistically significant effects on companies health plan offering strategies.

\subsection{Results from the Double-Adjusted, Bivariate Probit regression}

As shown by the Single-Adjusted Logistics regressions results from the previous subsection, when we account for the effects of the other variables, while assuming exogenous co-variates effects, then organizational management culture (whether individual, or group of employees or formal committee) is no longer statistically relevant in the contemporaneous plans offering decision by companies. Since our main objective is however to evaluate the effect of Organizational management culture, we proceed to relax the exogeneity assumption for the management culture variable, as a way of checking for potential mi-specification problems. The results of this recursively bivariate specification are shown in the third column of table (2).

The model is estimated using semi-parametric Gaussian Copula methods with bernoulli margins for each of the two binary equations. Figure (1) shows that the errors in the latent variable models for OrgManCu and OrgHPofS have a positive high correlation $\hat{\theta}=0.93$ that is highly statistically significant as shown by the $95 \%$ confidence interval $(0.430,0.987)$ in table $(2) . \hat{\tau}=0.76$ is also statistically significant as shown by its $95 \%$ confidence interval $(0.283,0.897)$. These indicate that the unobserved factors affecting groups or formal committee organizational management culture adoption by companies, also affect positively their multiple-plan offering strategy adoption. Furthermore the likelihood based gradient test for the absence of endogeneity(Terrell, 2002) with its p-value of 0.03 less than 0.05 confirms the presence of endogeneity.

Overall using the AIC and BIC criterion presented in table(2), the double-adjusted bivariate probit specification with $(\mathrm{AIC}=896.928$, and $\mathrm{BIC}=961.758)$ is preferred to the single-adjusted 
Logistic model with $(\mathrm{AIC}=1575.603$, and $\mathrm{BIC}=1663.586)$. This shows that relaxing the exogeneity assumption for the Organizational Management Culture variable provides for a better model specification than the first two models. For this preferred model, the convergence diagnostic checks for the trust region iteration algorithm (see (Malgorzata et al., 2016)) shows satisfactory convergence, as the largest absolute gradient value is close to zero (8.66912e-11) and the observed information matrix is positive definite.

As for the first equation of the model, capturing companies' choices of a Management Culture (OrgManCu), the results presented in the third column of table (2) show that the variables (company's for-profit status, and number of full-time employees) which enter the model parametrically, are all statistically significant at the $5 \%$ level. In fact, compared to companies that are in business for profits, those not-for profits have 0.61 times more chances of choosing a group or formal committee management culture over the individual management culture. Also compared to small size companies (0-49 full-time employees), those with medium size (50-499 full-time employees) and large size (500 or more employees) have respectively 0.75 and 1.60 times more chances of choosing a group or formal committee management culture over the individual management culture.

Regarding the second equation of the third model, capturing the adopted organizational health plan offering strategy (OrgHPofS), the results show that our primary variable of interest, the organizational management culture (OrgManCu), which was previously found to be insignificant in the single-adjusted Logistic regression, is now highly statistically significant, when we relax its exogeneity assumption. In fact, the estimated coefficient value of -1.58 suggests that compared to companies with an individual management culture, companies with groups or formal committee management cultures have 1.58 times less chances of choosing a multiple-plan offering strategy over the single plan strategy. This result is a bit contrary to what we were expecting, and hypothesized to start with. Therefore we reject our null hypothesis formulated in the introduction, and conclude that the evidence is enough to suggest that US companies with groups or formal committee management cultures do not make health plan offering decisions in ways theoretically consistent with the Ubuntu management style. Put differently, the probability of choosing a multiple plan offering strategy over a single plan strategy is not higher (but instead lower) for companies with groups and formal committee management cultures, compared to those with an individual management culture.

Now turning to the effects of the remaining co-variates entering parametrically the second equation of the third model, (company's for-profit status, Industry of operation, number of fulltime employees, the position of the respondent in the company, respondent's perception of ACA effect on company's plan offering decisions, whether or not the company has access to a source of quality information, and finally whether the plan(s) offered by the company have high deductibles), their signs and magnitudes are fairly consistent with those obtained under the single-adjusted Logistic regression results from the previous subsection.

In fact, in relation to company size, we see that companies with medium size (50-499 employees) 
, and those with large size ( 500 or more employees) have respectively 0.71 times and 1.64 times more chances of choosing a multiple-plan strategy over the single-plan strategy, compared to companies with a small size (0-49 employees). This results showing that as company size increases, the likelihood of multiple- plan strategy adoption increases, is in line with ACA mandates that employers with a certain size (50 or more full-time employees) must offer coverage to at least 70 percent of full-time employees or face financial penalties. It further suggests that the policy enacted through the ACA is being effective in expanding coverage to more employees.

In relation to the effect of the industry in which the company operates, the results suggest that only those operating in the service sector shows a relative statistically significant effect. In fact, relative to the companies in the manufacturing sector, those in the service sector are 0.37 times more likely to choose a multiple-plan strategy over the single plan strategy. This may be explained by the fact that employees in the service sector have relatively more diversified preferences for health insurance coverage than do those in the manufacturing sector where standardization tend to be common practice.

Regarding the effect of the respondents' position in the company, the results show that companies with a respondent occupying Executive or corporate Officer position, and Other Managers types all show a relative statistically significant effect over the Human resource manager position. In fact, compared to companies where the respondent is the Human Resource Manager, the companies where the respondent is of Other Management types, and those where the respondent is an executive or corporate officer have respectively 0.19 and 0.24 times less chances of choosing a multiple-plan offering strategy over the single plan strategy. The choice of the respondent which in this survey was based on the most knowledgeable employee criteria, implies then that for companies where the most knowledgeable employee is the Human Resources manager, the likelihood of choosing a multiple-plan strategy over the single-plan strategy is greater than that of any other types of company. The results consistently show however that employee's perception on ACA effect on company's behavior has no predictive value (statistically insignificant) on the actual chosen strategy by the company.

For the effects of the sources of quality information used by the company for its plan decision making, the results suggest there is a statistically significant value added to using HEDIS or NCQA as sources of quality information. In fact, compared to those using these sources, the companies not using them, and those unfamiliar with their existence are respectively 0.31 and 0.34 times less likely to choose a multiple-plan strategy over a single plan strategy. Once again showing the importance of quality information in complex decision making. Without much information companies are more inclined to making narrowed health plan choices.

Finally in relation to deductible plan costs, companies offering a plan with an annual single deductible of at least $\$ 1,250$ and a family deductible of at least $\$ 2,500$ for in-network have 0.58 times less chances of choosing a multiple-plan strategy over the single plan strategy. 


\section{Conclusion}

The motivation for this empirical analysis was the desire to understand the role that organizational management culture plays in companies' health plan offering strategies in the US, so as to see if US companies with groups or formal committee management cultures have health insurance offering choices similar to what is theoretically expected under Ubuntu style management. To this end, the paper used a random sample of 1,061 US business, along with three model specifications. The first was an un-ajusted logistic model, the second a single equation adjusted logistic model, and the third a system of two equations or adjusted Bivariate Probit model.

The results from the three specifications sequentially showed that the relationship between management culture and health plan offering strategies, is dependent on other relevant co-variates, which when left out, leads to omitted variables bias problems. However, when all variables are included but assumed to enter the relationship exogenously, this results in management culture not having any statistically significant effect on companies' decisions on the scope of health plan offering. When the exogeneity assumption was relaxed through the formulation of a recursively Bivariate Probit model, the system of two equations produced a highly significant management culture effect on the scope of plan offering.

This effect was however contrary to what we initially anticipated and formulated in our tested hypothesis for this study. As such, we reached the conclusion that the evidence was enough to suggest US companies with groups or formal committee management cultures did not have health insurance offering choices similar to what is theoretically expected under Ubuntu style management. Put differently, the probability of choosing a multiple plan offering strategy over a single plan strategy was not higher (but instead lower) for companies with groups and formal committee management cultures, compared to those with an individual management culture.

A possible observation that could be made from this result is that despite the acceptance and promotion of the Ubuntu philosophy around 2006 to 2009, by global leaders including former US president Bill Clinton, former Secretary of State Hillary Clinton, and US state department through ambassador Elizabeth Frawley Bagley as previously stated, the incorporation of this philosophy into US companies' culture, in relation to their health plan offering, has not fully materialized in the data as of 2014 .

Beyond this primary variable of interest, other factors such as: a company's for-profit status, Industry of operation, number of full-time employees, the position of the respondent in the company, whether or not the company has access to a source of quality information, and finally whether the plan(s) offered by the company have high deductibles were all shown to be important in explaining companies' health plan offering strategies in the United states.

On the opposite, employees' perceptions of the future effects of the ACA on their companies' health plan offering strategies have paradoxically failed to explain the contemporaneous health plan offering strategies adopted by US companies. This can be seen from both, the single-adjusted 
model, and the double-adjusted model, and is paradoxical because the survey used the most knowledgeable respondent criteria to select the person within each company for the interview. A plausible explanation for this might be that respondents did not base their forecast about the future effects of ACA on current company offering strategies, since they believed current strategies will be affected fundamentally as ACA is progressively implemented.

The fact as well that companies likelihood of multiple-plan strategy adoption increased with company size, suggests from a game theoretical stand point that the penalty treats presented by ACA mandates were successful at triggering companies' insurance extension responses for their employees. This contributed to making ACA a successful strategy for affordable care nationwide. However, with the recent elections and changes in government regime in the US, and the current government aim to repeal the ACA, it would be interesting to see how this policy reversal will redefine employers health plan offering strategies in the country. Future studies could investigate the effects of such changes on overall health plan affordability and coverage in the US.

A minor but worth mentioning limitation of this study comes from the sample which is only restricted to companies providing some private coverage, therefore as a selected sample, it excludes the situation where companies could choose not to provide any form of coverage and face the penalty instead. As such, the data could not allow us to capture the second step in the presented trivariate Ubuntu based Random Utility Model, which was then reduced to a bivariate model representing the first and last steps. It should be noted however that this limitation/restriction is not completely problematic in our analysis given the coercive nature of some ACA provisions that virtually make non compliance (failure to offer Insurance) fineable for certain size companies. If we assume that fines are devised to be more costly than compliance, then as rational optimizers companies will tend to choose the least costly option, which in this case would be compliance. Although to guarantee that compliance becomes the dominant strategy for companies, the government would have to have a good monitoring system, which in itself would be costly for the government. As monitoring and compliance raise costs to both government and companies respectively, the short term winners in this process will be the workers (health insurance consumers) which now benefit from greater extension. In the long-run however, if we consider the balance of power between government, companies and workers, this whole process would most likely end up with most of the costs being shifted back to the workers in the form of lower real wages. 


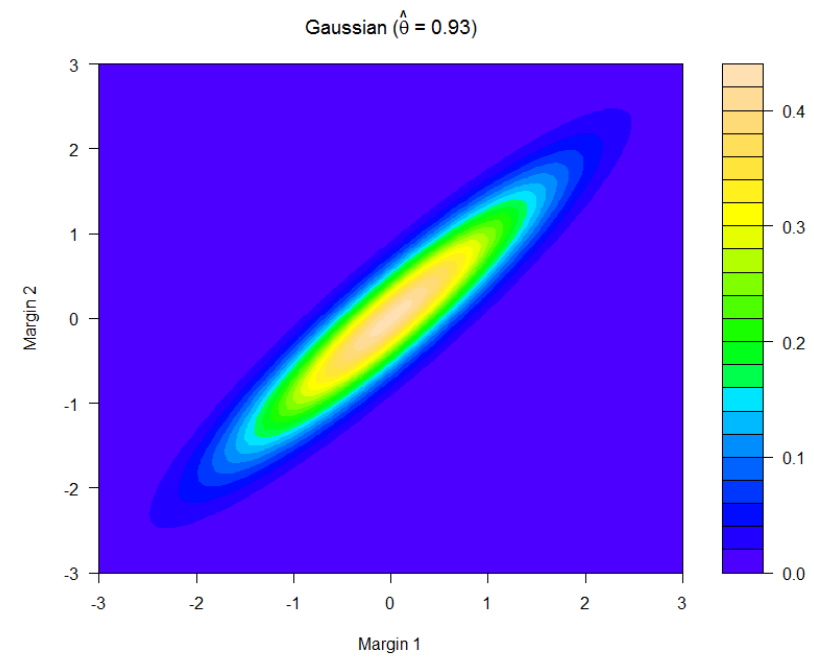

Figure 1: bi-variate distribution of Organizational Management Culture and Health Plan Offering Strategy 
Table 1: Summary Description for all the Variables used in the Econometric Modeling

\begin{tabular}{|c|c|c|}
\hline & Modalities & Frequencies out of 758 \\
\hline OrgManCu & $=1$ if Group or Committee culture & 586 \\
\hline OrgHPofS & $=1$ if Multiple-plan offering strategy & 369 \\
\hline \multicolumn{3}{|l|}{ ForProfitStatus } \\
\hline For-Profit (ref) & $=1$ if company is considered "profit" & 594 \\
\hline Not-For-Profit & $=1$ if company is considered "not-for-profit" & 164 \\
\hline \multicolumn{3}{|l|}{ Industry } \\
\hline Manuf (ref) & $=1$ if Manufacturing & 135 \\
\hline HealEd & $=1$ if Health and Education & 236 \\
\hline Serv & $=1$ if Services & 387 \\
\hline \multicolumn{3}{|l|}{ FulltimeEmp } \\
\hline Ssiz (ref) & $=1$ if small size Business $(0-49)$ & 261 \\
\hline Msiz & $=1$ if Medium size Business (50-499) & 273 \\
\hline Lsiz & $=1$ if Large size Business (500 or more) & 224 \\
\hline \multicolumn{3}{|l|}{ Position } \\
\hline HRM (ref) & $=1$ if Human Resources Manager & 243 \\
\hline $\mathrm{OM}$ & $=1$ if Other Managers & 393 \\
\hline $\mathrm{ECO}$ & $=1$ if Executive/corporate Officer & 122 \\
\hline \multicolumn{3}{|l|}{ ACAEffet } \\
\hline Easy (ref) & $=1$ if $\mathrm{ACA}$ Make it easier & 182 \\
\hline Hard & $=1$ if $\mathrm{ACA}$ Make it Harder & 284 \\
\hline None & $=1$ if $\mathrm{ACA}$ No Effect & 292 \\
\hline \multicolumn{3}{|l|}{ HEDISNCQA } \\
\hline Yes (ref) & $=1$ if company uses HEDIS or NCQA for information & 89 \\
\hline No & $=1$ if company does not use HEDIS or NCQA for information & 226 \\
\hline Unfa & $=1$ if unfamiliar with HEDIS or NCQA & 443 \\
\hline \multicolumn{3}{|l|}{ PlanStatus } \\
\hline HighDeduct (ref) & $=1$ if High Deductible Health Plan & 482 \\
\hline LowDeduct & $=1$ if Low Deductible Health Plan & 276 \\
\hline
\end{tabular}

Source: 2014 Survey of Businesses in the United States.

(ref) represents the reference category for the nominal variable with more than one level. 
Table 2: Un-Adjusted Logistic, Single-Adjusted Logistic, and Double-Adjusted Bivariate Probit Models Results

\begin{tabular}{|c|c|c|c|c|}
\hline & Un-Adjusted Model (1) & Single-Adjusted Model (2) & Double-Adjusted & Bivariate Probit (3) \\
\hline & Logistic & Logistic & OrgManCu & OrgHPofS \\
\hline CONST & $-0.548^{* * *}$ & 0.173 & 0.062 & $1.010^{* * *}$ \\
\hline & $(0.158)^{\dagger}$ & $(0.436)$ & $(0.081)$ & $(0.203)$ \\
\hline OrgManCu & $0.637^{* * *}$ & -0.097 & - & $-1.582^{* * *}$ \\
\hline & $(0.179)$ & $(0.129)$ & 一 & $(0.124)$ \\
\hline Not-For-Profit & & 0.034 & $0.610^{* * *}$ & 0.211 \\
\hline & & $(0.144)$ & $(0.150)$ & $(0.128)$ \\
\hline FulltimeEmpMsiz & & $0.471^{* * *}$ & $0.754^{* * *}$ & $0.712^{* * *}$ \\
\hline & & $(0.126)$ & $(0.115)$ & $(0.109)$ \\
\hline FulltimeEmpLsiz & & $1.289^{* * *}$ & $1.601^{* * *}$ & $1.637^{* * *}$ \\
\hline & & $(0.142)$ & $(0.164)$ & $(0.126)$ \\
\hline IndustryHealEd & & 0.294 & & 0.209 \\
\hline & & $(0.165)$ & & 0.125 \\
\hline IndustryServ & & $0.368^{* *}$ & & $0.239^{*}$ \\
\hline & & $(0.138)$ & & $(0.111)$ \\
\hline PositionOM & & -0.219 & & $-0.193^{*}$ \\
\hline & & $(0.122)$ & & $(0.091)$ \\
\hline PositionECO & & $-0.362^{*}$ & & $-0.241^{*}$ \\
\hline & & $(0.154)$ & & $(0.116)$ \\
\hline ACAEffetHard & & -0.105 & & -0.085 \\
\hline & & $(0.130)$ & & $(0.097)$ \\
\hline ACAEffetNone & & -0.160 & & -0.114 \\
\hline & & $(0.129)$ & & $(0.099)$ \\
\hline HEDISNCQANo & & $-0.395^{*}$ & & $-0.314^{*}$ \\
\hline & & $(0.180)$ & & $(0.137)$ \\
\hline HEDISNCQAUnfa & & $-0.418^{*}$ & & $-0.338^{* *}$ \\
\hline & & $(0.170)$ & & $(0.129)$ \\
\hline HighDeduct & & $-0.737^{* * *}$ & & $-0.582^{* * *}$ \\
\hline & & $(0.105)$ & & $(0.097)$ \\
\hline$\hat{\tau}$ & & & & 0.760 \\
\hline & & & & $(0.283,0.897)^{\dagger \dagger}$ \\
\hline$\hat{\theta}$ & & & & 0.930 \\
\hline & & & & $(0.43,0.987)$ \\
\hline $\mathrm{AIC}$ & 1041.200 & 1575.603 & & 896.928 \\
\hline $\mathrm{BIC}$ & 1050.465 & 1663.586 & & 961.758 \\
\hline
\end{tabular}

†† The 95\% confidence intervals for $\tau$ and $\theta$

$\dagger$ Standard deviation of the parameters in parentheses

${ }^{* * *}$ is $0.01 \%$ level significance; ${ }^{* *}$ is $1 \%$ level significance ${ }^{*}$ is $5 \%$ level significance 


\section{References}

Baicker, K., Levy, H., 2008. Employer health insurance mandates and the risk of unemployment. Risk Management and Insurance Review 11 (1), 109-132.

Blavin, F., Shartzer, A., Long, S. K., Holahan, J., 2015a. An early look at changes in employersponsored insurance under the affordable care act. Health Affairs 34 (1), 170-177.

Blavin, F., Shartzer, A., Long, S. K., Holahan, J., 2015b. Employer-sponsored insurance continues to remain stable under the aca: Findings from june 2013 through march 2015. Washington, DC: Urban Institute, http://hrms. urban. org/briefs/Employer-Sponsored-Insurance-Continues-toRemain-Stable-under-the-ACA. html (accessed 26 April 2016).

Blumberg, L. J., Buettgens, M., Feder, J., Holahan, J., 2012. Implications of the affordable care act for american business. Washington, DC: Urban Institute.

Blumenthal, D., 2006. Employer-sponsored health insurance in the united states - origins and implications. New England Journal of Medicine 355 (1), 82-88.

Carley, K. M., Behrens, D., 1999. Organizational and individual decision making. Handbook of Systems Engineering and Management. New York: Wiley-Interscience.

Collins, S. R., Davis, K., Ho, A., 2005. A shared responsibility: Us employers and the provision of health insurance to employees. INQUIRY: The Journal of Health Care Organization, Provision, and Financing $42(1), 6-15$.

English, J., 2002. Managing cultural differences to improve industrial efficiency. Building Research \& Information 30 (3), 196-204.

Eze, M., 2010. Intellectual history in contemporary South Africa. Springer.

Flynn, P., Wade, M., Holahan, J., 1997. State health reform: Effects on labor markets and economic activity. Journal of Policy Analysis and Management 16 (2), 219-236.

Fraser-Moleketi, G., 2009. Towards a common understanding of corruption in africa. Public Policy and Administration 24 (3), 331-338.

Goldstein, G. S., Pauly, M. V., 1976. Group health insurance as a local public good. In: The role of health insurance in the health services sector. NBER, pp. 73-114.

Hayfield, T., Racine, J. S., 2008. Nonparametric econometrics: The np package. Journal of Statistical Software $27(5)$.

URL http://www.jstatsoft.org/v27/i05/ 
Hirth, R. A., Baughman, R. A., Chernew, M. E., Shelton, E. C., 2006. Worker preferences, sorting and aggregate patterns of health insurance coverage. International journal of health care finance and economics $6(4), 259-277$.

Holtz-Eakin, D., Smith, C., 2010. Labor markets and health care reform: new results. In: American Action Forum. p. 2.

Hosmer, L. T., 1995. Trust: The connecting link between organizational theory and philosophical ethics. Academy of management Review 20 (2), 379-403.

Jackson, T., 2004. Management and change in Africa: A cross-cultural perspective. Routledge.

Johns, G., 2006. The essential impact of context on organizational behavior. Academy of management review 31 (2), 386-408.

Khomba, J. K., Kangaude-Ulaya, E. C., 2013. Indigenisation of corporate strategies in africa: lessons from the african ubuntu philosophy. China-USA Business Review 12 (7).

Look, K. A., Arora, P., 2015. Effects of the affordable care act's young adult insurance expansion on prescription drug insurance coverage, utilization, and expenditures. Research in Social and Administrative Pharmacy.

Look, K. A., Kim, N. H., Arora, P., 2016. Effects of the affordable care act's dependent coverage mandate on private health insurance coverage in urban and rural areas. The Journal of Rural Health.

Lutz, D. W., 2009. African ubuntu philosophy and global management. Journal of Business Ethics $84(3), 313-328$.

Malgorzata, W., Giampiero, M., Radice, R., 2016. Copula regression spline sample selection models. Journal of Statistical Software 71 (6), 1-65.

Mangaliso, M. P., 2001. Building competitive advantage from ubuntu: Management lessons from south africa. The Academy of Management Executive 15 (3), 23-33.

Maxwell, N. L., 2011. How do rules and costs affect a firm's setting of benefits? the case of health insurance and workforce skills. Advances in the Economic Analysis of Participatory and Labor-Managed Firms 12, 89.

Mbigi, L., Maree, J., 2005. Ubuntu, the spirit of African transformation management. Knowledge Resources. 
Muchie, M., Vertesy, D., Baskaran, A., Na-Allah, A. A.-S., 2009. Let africa lead: African transformational leadership for the 21st century business, reuel j. khoza (ed.): book review. African Journal of Science, Technology, Innovation and Development 1 (2 \& 3), 258-259.

O'Brien, E., 2003. Employers' benefits from workers' health insurance. Milbank Quarterly 81 (1), $5-43$.

Owolabi, K. A., Olu-Owolabi, F. E., 2009. Corporate social responsibility and the crisis of development in africa. Journal of Sustainable Development in Africa 10 (4), 218-232.

Public Affairs Research Center, U., 2014. Employer perspectives on the health insurance market: A survey of businesses in the united states. Inter-university Consortium for Political and Social Research [distributor], 2015-08-19, http://doi.org/10.3886/ICPSR36175.v1.

R Core Team, 2015. R: A Language and Environment for Statistical Computing. R Foundation for Statistical Computing, Vienna, Austria.

URL https://wWw.R-project.org/

Shane, D. M., Ayyagari, P., 2014. Will health care reform reduce disparities in insurance coverage?: evidence from the dependent coverage mandate. Medical care 52 (6), 528-534.

Shane, D. M., Ayyagari, P., 2015. Spillover effects of the affordable care act? exploring the impact on young adult dental insurance coverage. Health services research 50 (4), 1109-1124.

Sigger, D., Polak, B., Pennink, B., 2010. Ubuntu'or 'humanness' as a management concept. CDS Research Paper 29.

Smith, J. G., Lindsay, J. B., 2014. The research. In: Beyond Inclusion. Springer, pp. 17-32.

Terrell, G. R., 2002. The gradient statistic. Computing Science and Statistics 34 (34), 206-215.

Tutu, D., 2012. No future without forgiveness. Random House.

Tutu, D., Abrams, D., 2004. God has a dream: A vision of hope for our time. Image.

Vistness, J. P., Monheit, A. C., 1999. Health insurance availability at the workplace. Journal of human resources 34 (4), 770-785.

Wanasika, I., Howell, J. P., Littrell, R., Dorfman, P., 2011. Managerial leadership and culture in sub-saharan africa. Journal of World Business 46 (2), 234-241. 